\title{
The response of vegetation dynamics of the different alpine grassland types to temperature and precipitation on the Tibetan Plateau
}

\author{
Jian Sun • Xiaojing Qin • Jun Yang
}

Received: 25 August 2015 / Accepted: 25 November 2015 /Published online: 9 December 2015

(C) Springer International Publishing Switzerland 2015

\begin{abstract}
The spatiotemporal variability of the Normalized Difference Vegetation Index (NDVI) of three vegetation types (alpine steppe, alpine meadow, and alpine desert steppe) across the Tibetan Plateau was analyzed from 1982 to 2013. In addition, the annual mean temperature (MAT) and annual mean precipitation (MAP) trends were quantified to define the spatiotemporal climate patterns. Meanwhile, the relationships between climate factors and NDVI were analyzed in order to understand the impact of climate change on vegeta-
\end{abstract}

Xiaojing Qin contributed equally to this work.

J. Sun $\cdot$ X. Qin · J. Yang $(\bowtie)$

Key Laboratory of Ecosystem Network Observation and Modelling, Institute of Geographic Sciences and Natural

Resources Research, Chinese Academy of Sciences,

Beijing 100101, China

e-mail: Yangj@igsnrr.ac.cn

J. Sun

e-mail: sunjian@igsnrr.ac.cn

X. Qin

e-mail: Xiaojingqin513@163.com

X. Qin

Institute of Land and Resources, China West Normal University, Nanchong, Sichuan, China

J. Yang

Center for Environmental Remediation, Institute of Geographic Sciences and Natural Resources Research, Chinese Academy of Science, Beijing 100101, China tion dynamics. The results indicate that the maximum of NDVI increased by 0.3 and $0.2 \%$ per 10 years in the entire regions of alpine steppe and alpine meadow, respectively. However, no significant change in the NDVI of the alpine desert steppe has been observed since 1982. A negative relationship between NDVI and MAT was found in all these alpine grassland types, while MAP positively impacted the vegetation dynamics of all grasslands. Also, the effects of temperature and precipitation on different vegetation types differed, and the correlation coefficient for MAP and NDVI in alpine meadow is larger than that for other vegetation types. We also explored the percentages of precipitation and temperature influence on NDVI variation, using redundancy analysis at the observation point scale. The results show that precipitation is a primary limiting factor for alpine vegetation dynamic, rather than temperature. Most importantly, the results can serve as a tool for grassland ecosystem management.

Keywords Vegetation dynamics · Alpine grassland · Normalized difference vegetation index · Precipitation . Temperature · Tibetan Plateau

\section{Introduction}

The grassland ecosystem is an important component of the terrestrial ecosystem. Vegetation coverage serves as the best indicator to monitor the effect of climate on the 
growth of plants (Gurgel and Ferreira 2003). Furthermore, climate change has become a critical point in global change research (Ding et al. 2013). Dramatic climate change has been confirmed over the past several decades in several studies (Namgail et al. 2012) with an observed increase of $0.6 \pm 0.2{ }^{\circ} \mathrm{C}$ in global mean surface temperature (Zhao et al. 2004), leading to more rapid melting of ice, especially in regions of high altitude. The alpine ecosystem is particularly sensitive to climate change, as demonstrated by the degradation trend of alpine meadow and steppe found from 1986 to 2000 (Wang et al. 2007). For example, the degradation of alpine grassland ecosystems has reached $82-86 \%$ in the headwater area of the Yangtze River (Wang et al. 2011). As the "world's third pole," and as a region minimally affected by human activity, the Tibetan Plateau has fragile vegetation that is sensitive to climate change (Nowak and Nobis 2012).

The dynamics of vegetation were significantly influenced by climate change on the Tibetan Plateau (Wang et al. 2015). Alpine grassland covers an area of about $1.525 * 10^{6} \mathrm{~km}^{2}$, accounting for $59.28 \%$ of the Tibetan Plateau. Therefore, the vegetation dynamic has a particular function in the global carbon cycle (Piao et al. 2006). Some researchers suggested that precipitation plays a more important role than temperature in arid or semi-arid regions like the Tibetan Plateau (Sun et al. 2013b). For example, monsoon precipitation controls vegetation distribution in summer (Shen et al. 2008). In addition, no significant correlation has been found among the maximum vegetation index in growing season and temperature and precipitation across the Tibetan Plateau (Shen et al. 2014). Moreover, the monthly correlation coefficient for monthly average Normalized Difference Vegetation Index (NDVI) and precipitation is 0.75 , which is greater than the correlation coefficient of 0.63 for monthly average NDVI and temperature in the Lhasa area (Chu et al. 2007). Previous studies have analyzed NDVI variations and their relationships with temperature and precipitation in the Tibetan Plateau (Chu et al. 2007; Xu et al. 2011; Ding et al. 2013; Wang et al. 2015), but correlations between NDVI in different vegetation types and climatic factors have not been observed. In actuality, different vegetation types respond differently to temperature and precipitation. In total, the three types of vegetation response to precipitation were stronger than temperature, and the alpine meadow was the most sensitive to climate factors. However, only limited research has been conducted on this issue.

Clearly, the ways that different vegetation types of the Tibetan Plateau respond to climate changes is a scientific research area of concern. The main purpose of this study is (1) to explore the long-time (1982-2013) changes in annual mean temperature and annual mean precipitation in different vegetation types (alpine steppe, alpine meadow, and alpine desert steppe); (2) to identify the spatiotemporal patterns of NDVI in different vegetation types; and (3) to analyze the relationship between NDVI and temperature and precipitation in different vegetation types.

\section{Materials and methods}

\section{Study area}

The Tibetan Plateau, with an extreme altitude (1000$8846 \mathrm{~m}$ ), is the highest plateau in the world (Rana et al. 2011). The mountainous natural landscape presents vertical variations with the rise in elevation, ranging from the rainforest to alpine snow and ice. Alpine steppe (AS), alpine meadow (AM), alpine desert steppe (ADS), wetland, and forest are the main vegetation types on the Tibetan Plateau (Fig. 1). Moreover, grassland resources in the study area are rich, covering one third of the total area of grassland. Alpine vegetation is very important to the lives of humans and animals on the Tibetan Plateau, as well as to the global carbon budget (Wang et al. 2011).

Three vegetation types (AS, AM, and ADS) were selected for this study. As shown in Fig. 1, the alpine steppe is mainly distributed in northern Tibet and east and west of Qinghai. The area of AS amounts to 0.71 million $\mathrm{km}^{2}$; the distribution of alpine meadow is more scattered, mainly in areas of mutual transition in three provinces (Qinghai, Tibet, and Sichuan) and northeast of Qinghai, with an area of 0.65 million $\mathrm{km}^{2}$. Desert steppe, with an area of 0.22 million $\mathrm{km}^{2}$, is mainly located south of Xinjiang and the Qaidam Basin.

Datasets and analysis methods

Meteorological data, including daily meteorological data (temperature, precipitation), were collected from the 


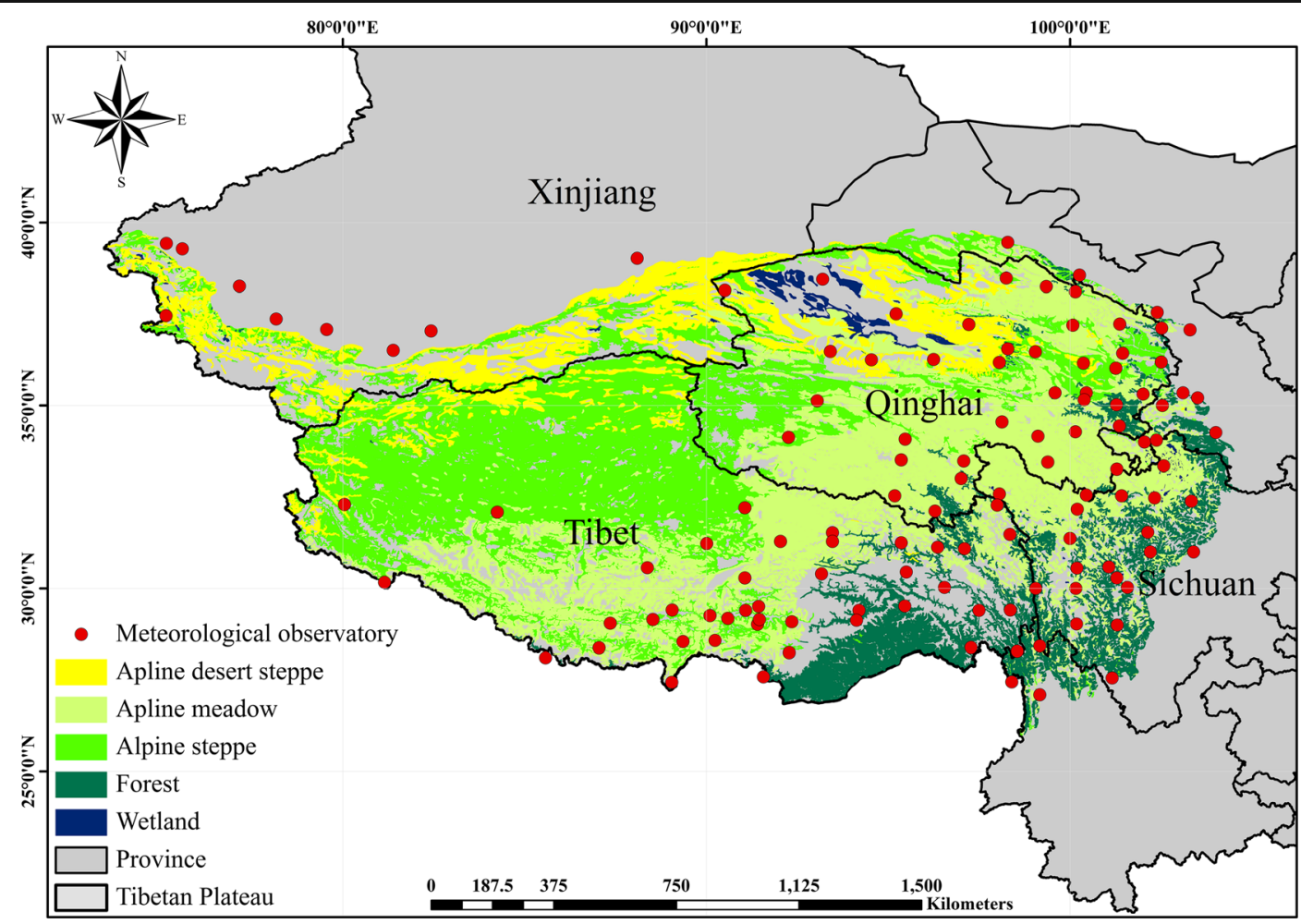

Fig. 1 The distribution of vegetation types and meteorological observatories across the Tibetan Plateau

Meteorology Information Center of the Chinese National Bureau of Meteorology, with 122 weather stations across the Tibetan Plateau. After the early stage of the research process, we obtained data containing annual mean temperature (MAT) and annual mean precipitation (MAP). Then, a variability map of MAT and MAP covering the entire area was created via inverse distance weighting, using ArcGIS. Overlaying the map of the three types of vegetation classified from China's vegetation types with the above temperature and precipitation map allowed us to display the temporal variability of MAT and MAP in different vegetation types.

The NDVI data were downloaded from the Western Date Center. They derived from global inventory monitoring and modeling studies (GIMMS) from 1982 to 2013, and a working group provided the third generation of NOAA/AVHRR remote sensing data. The spatial resolution is $8 \mathrm{~km} \times 8 \mathrm{~km}$, and the time resolution is 15 days, with Albers projection methods used to project the area of the cone. To remove noise from the remote sensing data caused by clouds or weather, the maximum value composite (MVC) method was used as one step in the process. Over the past 32 years, the linear trend coefficient was used to identify the changed tendencies of annual maximum NDVI and climate factors (MAT and MAP) (Sun et al. 2013b).

$$
S L O P E=\frac{n \times \sum_{i=1}^{n} i \times x_{i}-\sum_{i=1}^{n} i \times \sum_{i=1}^{n} x_{i}}{n \times \sum_{i=1}^{n} i^{2}-\left(\sum_{i=1}^{n} i\right)^{2}}
$$

where $n$ is the natural time sequence number $1,2,3, \ldots$, $n$ year; $i$ refers to the natural number $1,2,3, \ldots, 26$ corresponding to the year from 1982 to 2013; and $x_{i}$ identifies the object, such as NDVI, temperature, or precipitation, in year $i$.

The SLOPE value is positive or negative when the change trend of the elements analyzed is ascending or descending, respectively. Moreover, we obtained the spatiotemporal relationship between the mean value of NDVI and the annual temperature or precipitation from 1982 to 2013 on the Tibetan Plateau. Meanwhile, we explored the percentage of precipitation and temperature in NDVI variation using redundancy analysis (RDA) at an observation point scale. RDA is a correlation analysis method that calculates the percentage of influence on variable when the factors are more than two; at the same time, it could show the single impact of temperature and 
precipitation on NDVI. The RDA was then computed using the vegan package (R Core Development Team, $\mathrm{R}$ Foundation for Statistical Computing, Vienna, Austria). In addition, the operations mentioned above were all implemented in ArcGIS 9.3 (ESRI, Inc., Redlands, CA, USA) and SigmaPlot for Windows version 10.0 (Systat Software, Inc., Chicago, IL, USA).

\section{Results}

Spatiotemporal changes in temperature and precipitation from 1982 to 2013

The figures show changing trends in MAT and MAP in the AS (Fig. 2a), AM (Fig. 2b), and ADS (Fig. 2c). Over the past 32 years (1982-2013), the study area has exhibited an obvious warming trend. The mean temperature increased by $0.70{ }^{\circ} \mathrm{C}$ per 10 years $\left(R^{2}=0.93\right.$, $P<0.0001), 0.68{ }^{\circ} \mathrm{C}$ per 10 years $\left(R^{2}=0.96\right.$, $P<0.0001)$, and $0.75{ }^{\circ} \mathrm{C}$ per 10 years $\left(R^{2}=0.89\right.$, $P<0.0001)$ in AS, AM, and ADS, respectively. By the year 2013, the MAT had increased by 1.82, 1.70, and $1.64{ }^{\circ} \mathrm{C}$ in AS, AM, and ADS, respectively. Meanwhile, MAP also underwent noticeable change in AS $\left(R^{2}=\right.$ $0.73, P<0.0001)$, AM $\left(R^{2}=0.63, P<0.0001\right)$, and $\operatorname{ADS}\left(R^{2}=0.68, P<0.0001\right)$ from 1982 to 2013 .

The slope of the MAT and MAP in three vegetation type regions is shown in Fig. 3. In Fig. 3a, the rate of MAT change appears alternately from west to east. The mean value of the slope was $0.70{ }^{\circ} \mathrm{C}$ per 10 years. Meanwhile, the maximum value was $2.48^{\circ} \mathrm{C}$ per 10 years
Fig. 2 Anomaly of temperature and precipitation in different vegetation types from 1982 to 2013. (a and b: alpine steppe; $\mathbf{c}$ and $\mathbf{d}$ : alpine meadow; $\mathbf{e}$ and $\mathbf{f}$ : alpine desert steppe)

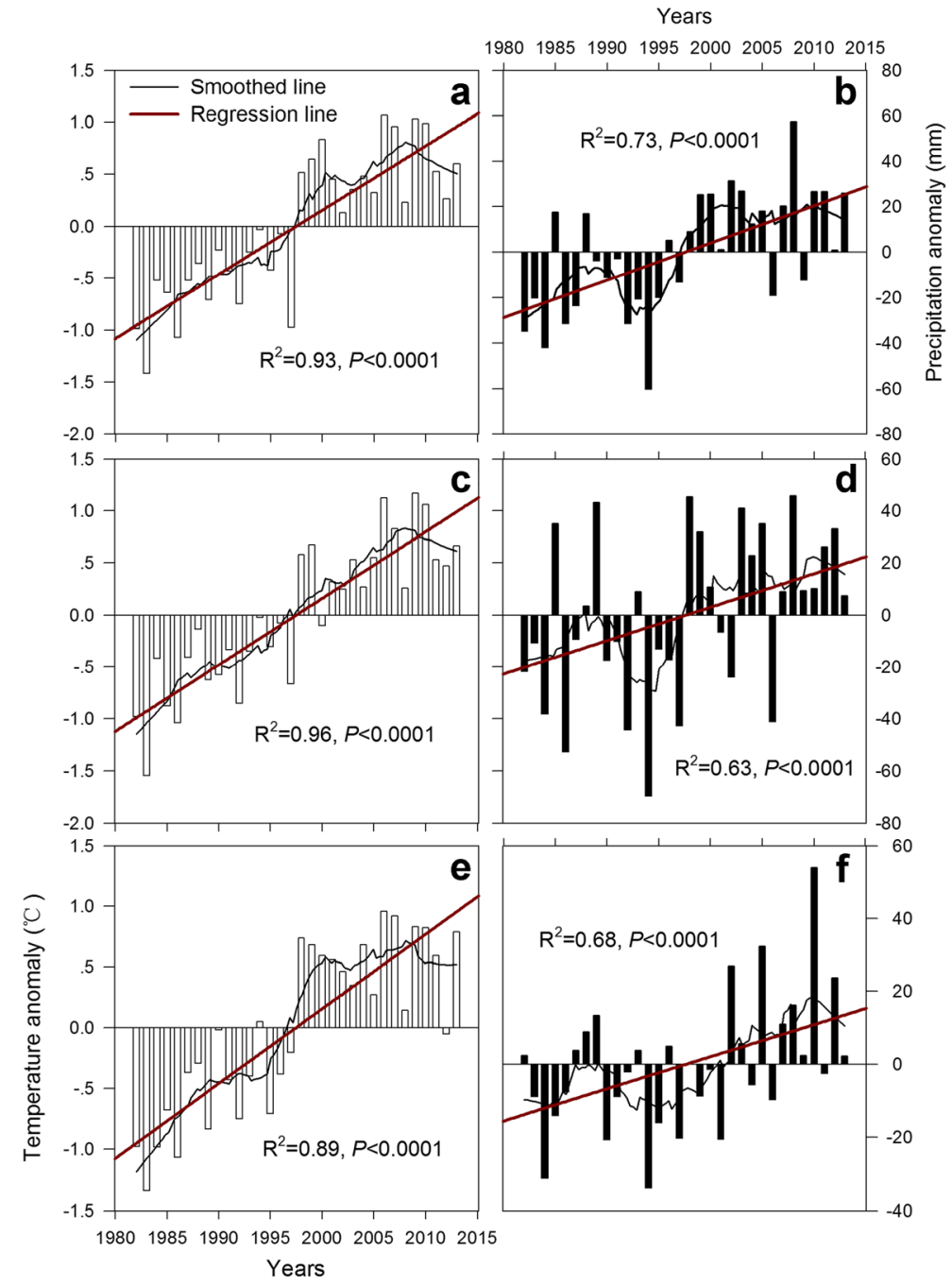


and was found on the Ali Plateau and in the western Qinghai Plateau, but the minimum value was $-3.21{ }^{\circ} \mathrm{C}$ per 10 years for areas at the edge of Tibet. The maximum precipitation was $24.55 \mathrm{~mm}$, which was found in northern Tibet (Fig. 3b). For AM, the mean value of the slope was $0.68{ }^{\circ} \mathrm{C}$ per 10 years (Fig. 3c) and $8.42 \mathrm{~mm}$ per
10 years (Fig. 3d). In addition, in terms of temperature, AM vegetation south of Qinghai showed a significant increasing trend. Furthermore, the temperature in the regions of ADS vegetation demonstrated a slight increasing trend (Fig. 3e), and in regions of ADS, the precipitation varied from -31.29 to $34.23 \mathrm{~mm}$ (Fig. 3f).

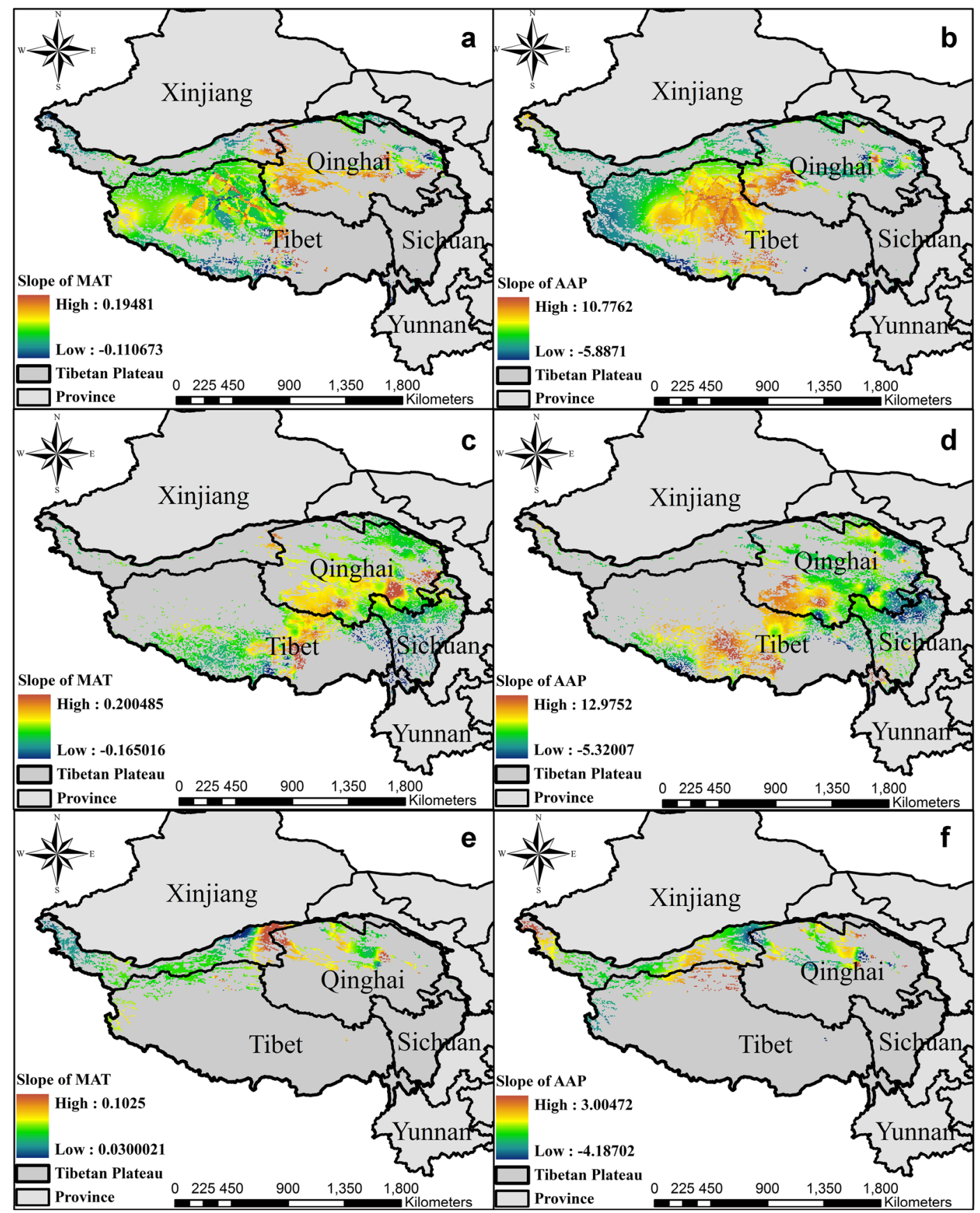

Fig. 3 Variations of temperature and precipitation in different vegetation types on the Tibetan Plateau. (a slope of MAT in AS; b slope of MAP in AS; $\mathbf{c}$ slope of MAT in AM; $\mathbf{d}$ slope of MAP in AM; e slope of MAT in ADS; $\mathbf{f}$ slope of MAP in ADS) 


\section{Spatiotemporal changes of NDVI}

Figure 4 shows the altered trends from 1982 to 2013 of NDVI in the Tibetan Plateau (Fig. 4a), AS (Fig. 4b), AM (Fig. 4c), and ADS (Fig. 4d). The four smooth curves resemble development, though the fitting lines were increased in the Tibetan Plateau $\left(R^{2}=0.08, P<0.01\right)$, AS $\left(R^{2}=0.37\right.$, $P<0.001)$, and AM $\left(R^{2}=0.06, P<0.05\right)$, except for ADS.

The spatial trends of AS, AM, and ADS across the Tibetan Plateau from 1982 to 2013 were analyzed (Fig. 5). The results indicated that most of the alpine steppe in the Tibetan Plateau did not experience significant variation in annual maximum NDVI during this period; the insignificant recovery area was larger than that of insignificant degradation (refer to Table 1). Figure 5b shows the changes in AM, and a small zone located in Qinghai indicated significant recovery, but the area of insignificant degradation increased compared with that of AS (Fig. 5a). The slope of NDVI showed an insignificant change trend in ADS (Fig. 5c).

The relationship between NDVI and temperature/ precipitation for three vegetation types

The temporal dynamics of the correlation coefficient were obtained (Fig. 6) based on the correlation coefficients between the NDVI (three vegetation types: AS, AM, and ADS) and the AMT and MAP on the Tibetan Plateau from 1981 to 2013. A positive correlation was found between the temperature and alpine steppe in several zones (the boulders of Qinghai, Xinjiang, and Tibet) (Fig. 7a). However, most regions showed a negative correlation between temperature and alpine steppe (Fig. 6a). Nevertheless, the correlation between MAP and NDVI was significantly positive in most parts of the alpine steppe (Fig. 6b). Figure $6 a$ shows the distribution of correlation coefficients between temperature and NDVI in AM, and the coefficient correlation varied from 0.05 to 0.5 in AM; thus, the temperature has a positive effect on the NDVI. For the relationship between MAP and NDVI in AM, the regions with a coefficient between -0.05 and 0.5 were located in the boulders of Qinghai and Sichuan (Fig. 6b). Overall, MAT and MAP gave rise to a similar insignificant impact on NDVI in ADS (Fig. 6a, b).

To identify the determining factors for NDVI in the different vegetation types, we extracted NDVI values from the corresponding meteorological stations from 1982 to 2013. The correlation coefficient between MAT and NDVI of AS, AM, and ADS (Fig. 6a) vegetation types was low and related linearly with $R^{2}=0.19 \quad(P<0.0001, n=1607)$, $0.06(P<0.0001, n=1459)$, and $0.21 \quad(P<0.0001$, $n=477)$, respectively. In contrast, stronger positively correlated trends were observed between NDVI and precipitation in AS, AM, and ADS (Fig. 6b) with $R^{2}=0.63 \quad(P<0.0001, n=1607), 0.75 \quad(P<$ $0.0001, n=1459)$, and $0.52(P<0.0001, n=477)$, respectively, and the MAP yielded the greatest influence on the alpine meadow.

The relative contributions of MAP and MAT are mapped as bar graphs in Fig. 7, based on the observatory stations across the Tibetan Plateau from 1982 to 2013. In total, the MAP produced
Fig. 4 Anomaly of NDVI in different vegetation types from 1982 to 2013. (a Tibetan Plateau; b alpine steppe; c alpine meadow; d alpine desert steppe)
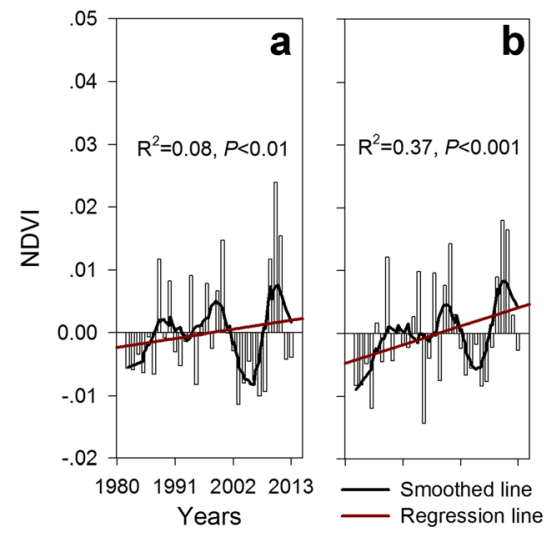
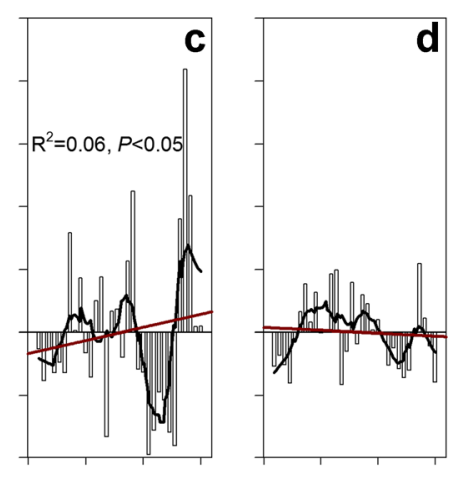
Fig. 5 Change trends of NDVI and the significant test in time series for different vegetation types on the Tibetan Plateau. (a slope of NDVI in AS; $\mathbf{b}$ slope of NDVI in AM; $\mathbf{c}$ slope of NDVI in ADS)

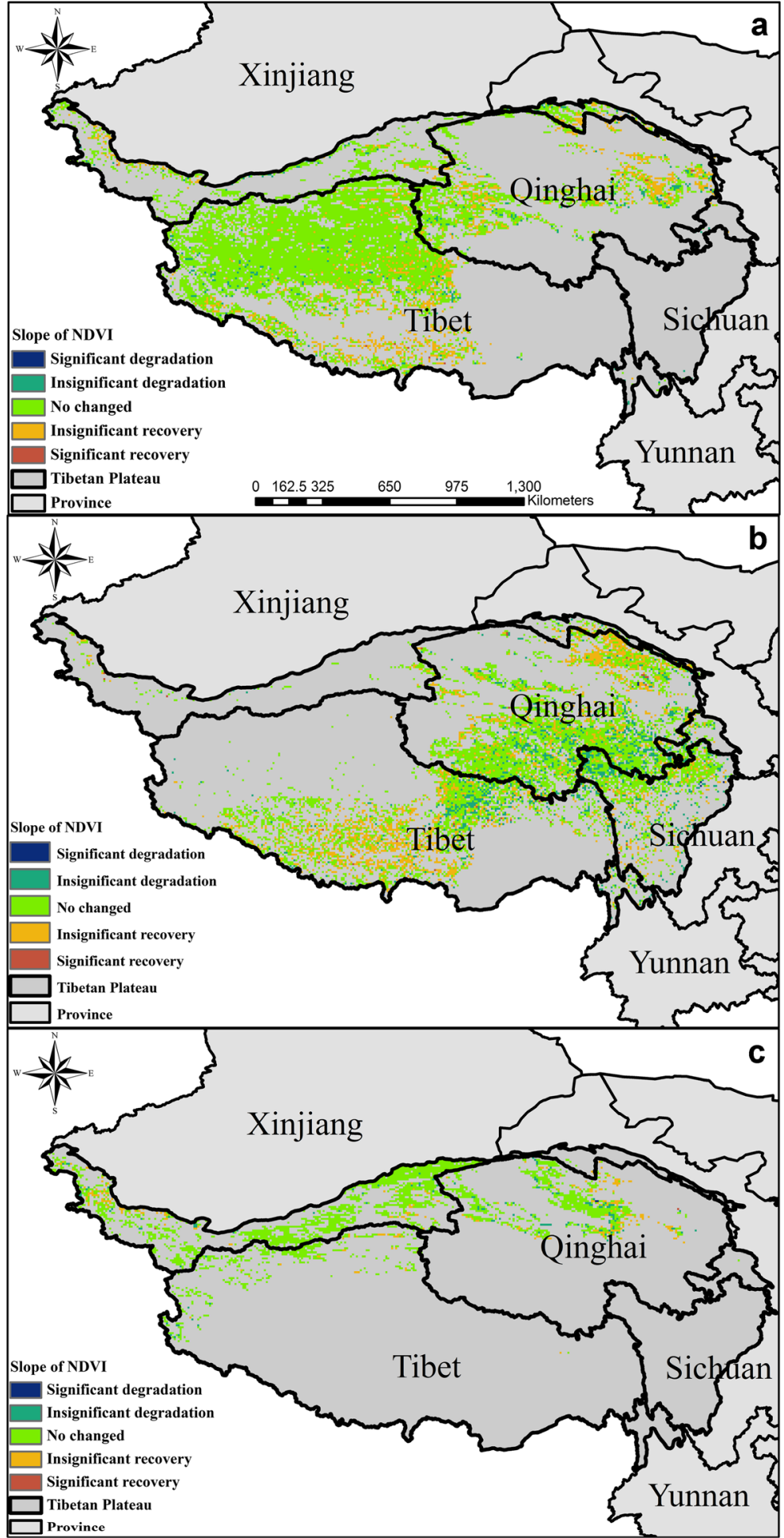

a greater effect on NDVI compared with MAT, especially in the northeastern plateau. In addition, the climatic factors played a more important role in AS than AM. Apparently, MAP explained that 
Table 1 Classified result of maximum Normalized Difference Vegetation Index (MNDVI) change simulated from 1982 to 2013 (Sun et al. 2013b)

\begin{tabular}{lll}
\hline Items & $\begin{array}{l}\text { The trend of MNDVI } \\
\text { change }\end{array}$ & Status \\
\hline Category & Slope $\leq-0.0091$ & $\begin{array}{l}\text { Extremely significant } \\
\text { degradation }\end{array}$ \\
$-0.0091 \leq \mathrm{Slope} \leq-0.0046$ & Significant degradation \\
$-0.0045 \leq \mathrm{Slope} \leq-0.0010$ & Insignificant degradation \\
$-0.0009 \leq \mathrm{Slope} \leq 0.0009$ & No change \\
$0.0010 \leq \mathrm{Slope} \leq 0.0045$ & Insignificant recovery \\
$0.0046 \leq \mathrm{Slope} \leq 0.0090$ & Significant recovery \\
Slope $\geq 0.0090$ & Extremely significant \\
& recovery \\
\hline
\end{tabular}

the variations of NDVI at the Dulan, Chaka, Qianning, and Tuotuohe stations were 29.02, 26.31, 24.65, and $17.84 \%$, respectively. Different from MAP, the MAT explained the variations of NDVI at Maqu, Zuogong, Qingshuihe, and Dexin stations as $19.36,18.85,18.04$, and $16.59 \%$, respectively. Generally, the explained percentage of both MAP and MAT in NDVI variation was higher than the single factor (e.g., MAP or MAT), and the value varied from 0.03 to 32.03 .
In terms of MAT, the effect was greatest in AS, which achieved $6.85 \%$, and it was 4.71 and $0.75 \%$ in $\mathrm{AM}$ and $\mathrm{ADS}$, respectively.

\section{Discussions}

Spatiotemporal changes in temperature and precipitation among three types of vegetation

The mean temperature increased by $0.68-0.75{ }^{\circ} \mathrm{C}$ per 10 years in alpine grasslands, which was higher than the increment $\left(0.4-0.67{ }^{\circ} \mathrm{C}\right)$ in air temperature per 10 years across the Tibetan Plateau (Wang et al. 2011). However, severe temporal variabilities of precipitation were found in the center of Tibet, with an average increased value of $15.55 \mathrm{~mm}$ per 10 years. Also, the increase in annual air temperature was found to be higher in the northeastern Tibetan Plateau than in other regions. The above results were verified in another study, which found that the most obvious warming and decrease in precipitation occurred across the northeastern Tibetan Plateau (Zhao et al. 2004). In addition, the climate trend of the southern Tibetan Plateau has shown a warm and

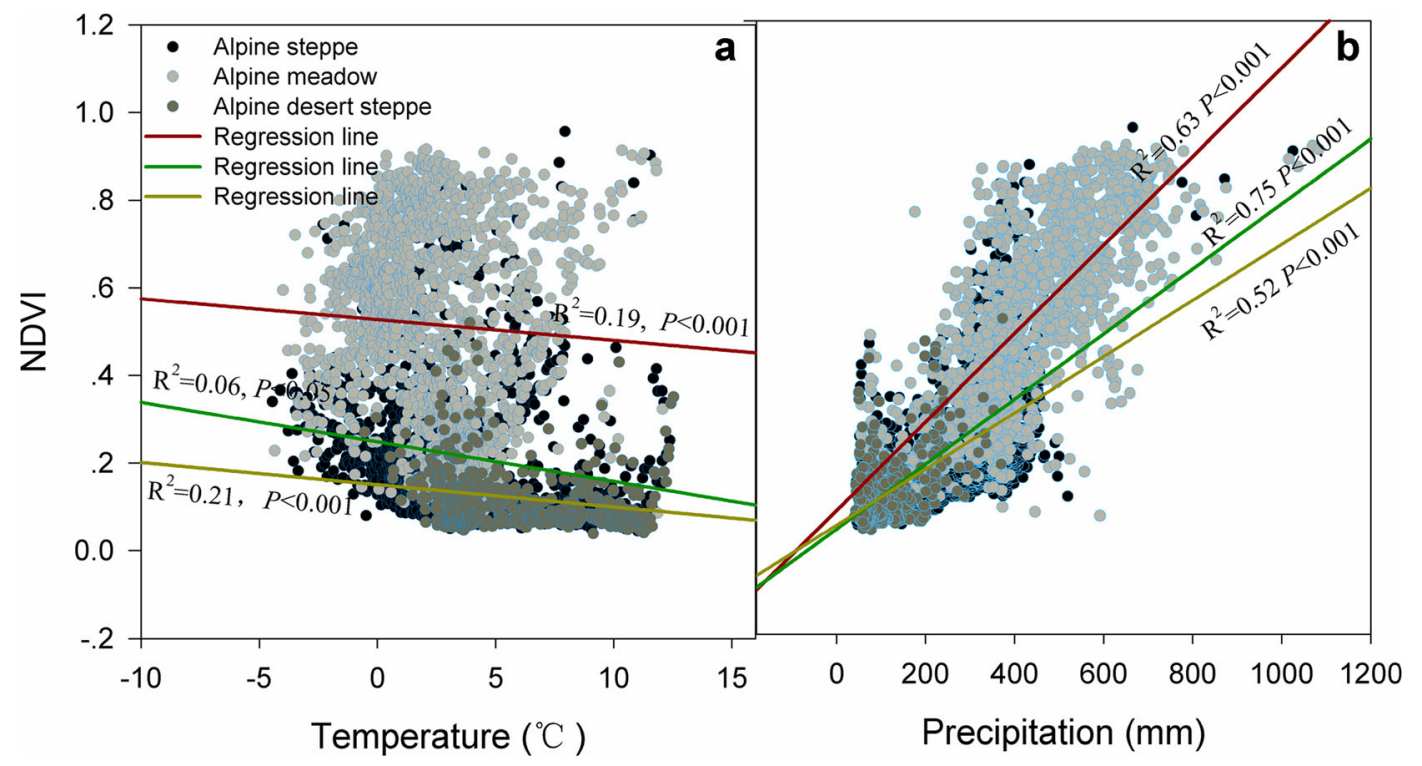

Fig. 6 Correlated relationships between NDVI and climate factors (MAT and MAP) in different grassland types from 1982 to 2013. The dark red solid line denotes the regression line in AM, the dark green denotes the regression line in ADS. a The relationships between MAT and NDVI in AS, AM, and ADS, respectively. b The relationships between MAT and NDVI in AS, AM, and ADS, respectively 


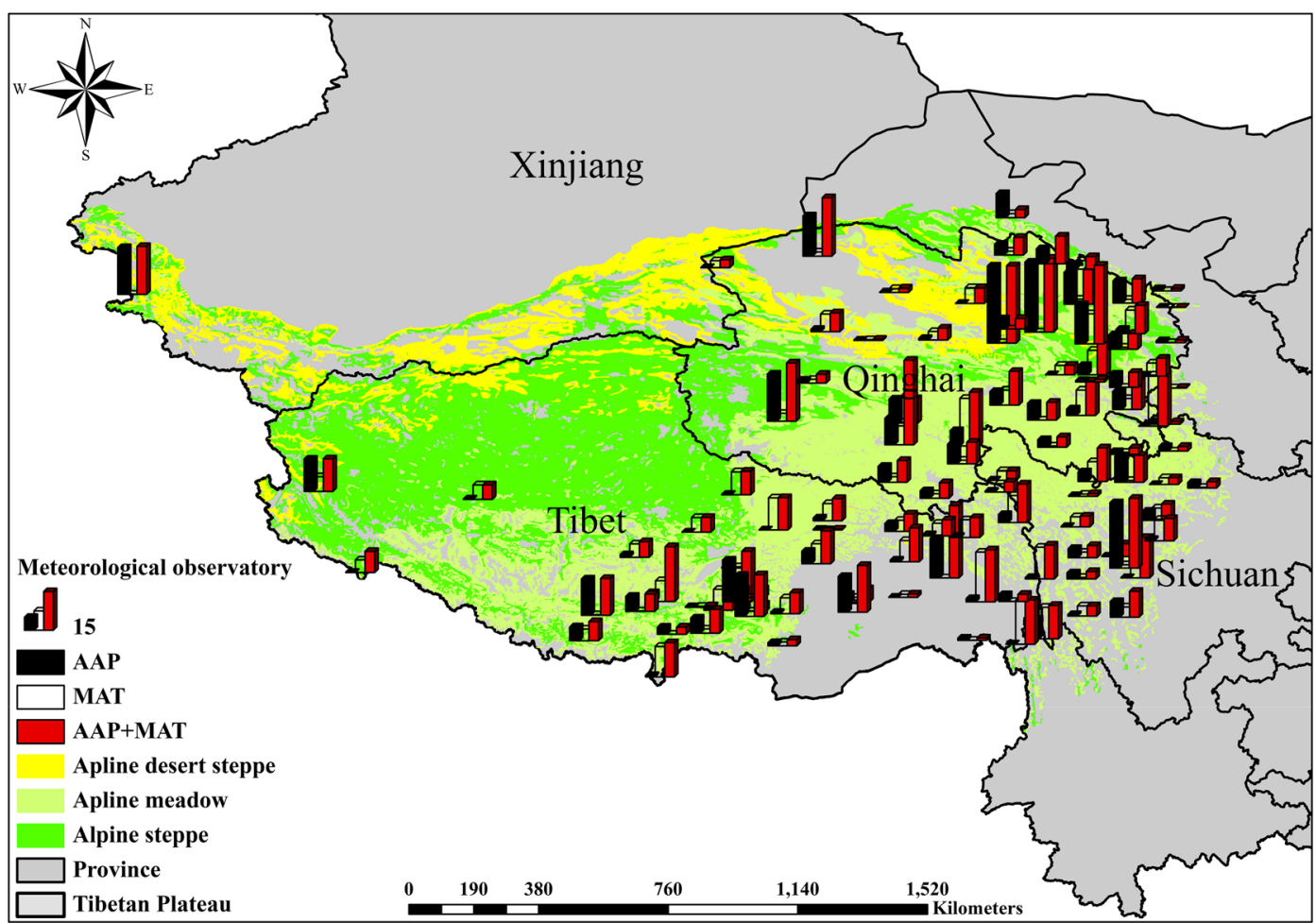

Fig. 7 Explained percentage of MAP and MAT in variations of NDVI based on each observatory station in the Tibet Plateau from 1982 to 2013

humid annual tendency (Venn et al. 2011), and we also found that the slope of precipitation increased in this area. For temporal patterns, obvious warming trends (Fig. 3) were shown in alpine steppe, alpine meadow, and alpine desert steppe over the past 32 years. Precipitation was less than $200 \mathrm{~mm}$ in the northwestern part of the Tibetan Plateau (Ding et al. 2007) because the southwest warm and humid air flow, the southeast monsoon, and the Siberian High regulated the precipitation. Thus, the slight increment resulted in a drastic changing trend during the observed period. An increasing precipitation trend also was found in the alpine steppe region.

\section{Spatiotemporal changes of NDVI}

The temporal patterns of NDVI in alpine steppe, alpine meadow, and Tibetan Plateau steppe experienced significant variations, with the change trend increased during 1982-2013 (Fig. 4). However, the NDVI of the alpine desert steppe rose first and then declined sharply, but in recent years, the vegetation cover of the alpine desert steppe gradually became better and better. The same change tendency of NDVI was demonstrated in the study region (Sun et al. 2013b). Moreover, our result is in line with the report of Shen et al. (2014), which suggested that the mean maximum enhanced vegetation index (EVI) also showed an insignificant decreasing trend over the entire Tibetan Plateau. Thus, there was no significant degradation or significant recovery for most alpine grasslands (Fig. 5). In terms of the alpine steppe, the NDVI was not changed in most areas and the alpine meadow had insignificant recovery. It should be noted that the alpine desert steppe has shown significant degradation in Qinghai province. Furthermore, this fact has been confirmed (Gao et al. 2010).

The relationship between NDVI and temperature/ precipitation for three vegetation types

Vegetation of the Tibetan Plateau has been shown to be very sensitive and vulnerable to environmental change (Sun et al. 2014), because of the high altitude and complex topography. The growth and distribution of plants depend heavily on local climate conditions (Cui and Graf 2009). The region's climate exhibited a 
tendency toward desiccation, which seriously affected the normal growth and reproduction of vegetation (Wang et al. 2007). Thus, on the Tibetan Plateau, the alpine desert steppe was more sensitive to temperature changes than the alpine steppe and alpine meadow (Fig. 6a-c). Some reports also hold that the positively correlated relationship between NDVI and surface heat source is more remarkable in the western than the eastern Tibetan Plateau (Caccianiga et al. 2011). However, $\mathrm{Xu}$ et al. (2008) suggested that the annual mean vegetation cover trends were significantly out of phase with the increase in air temperature. It is noteworthy that there is a clear positive relationship between the NDVI increments and precipitation on the Tibetan Plateau (Immerzeel et al. 2005). We also observed significant positive correlations between precipitation and NDVI for the alpine steppe, alpine meadow, and alpine desert steppe. Meanwhile, precipitation has more of a positive correlation than the temperature in these regions. As a matter of fact, precipitation was a critical factor in controlling the primary productivity in most alpine grasslands (Sun et al. 2013b). Our findings (Fig. 6) reinforce the idea that precipitation is a limited factor that controls the functions of ecosystems, particularly in arid and semi-arid grassland ecosystems (Liu et al. 2014). Moreover, the different vegetation types had different responses to the changes in climatic factors (Wang et al. 2011); NDVI of alpine meadow was more sensitive to precipitation changes than alpine steppe and alpine desert steppe (Fig. 7). Previous research suggested that the water may be adequate for the meadow and thus the precipitation did not become a limiting factor (Sun et al. 2013a). But further research is needed to explore the effects of precipitation on different grassland types.

\section{Conclusions}

As described above, the impact of temperature and precipitation on alpine grassland types clearly differs. All the NDVI of different grassland types were limited by temperature and precipitation, and the negative and positive effects of temperature and precipitation on the NDVI in these alpine grasslands were verified. In arid and semi-arid grassland ecosystems, we concluded that precipitation was a primary factor in controlling the vegetation dynamics. Moreover, aside from the natural conditions, the permafrost environment (Schaphoff et al. 2013) and human activities (Zhang et al. 2010) are the major contributing factors that control the dynamics of the alpine grassland ecosystem, and the increase in human population and activities caused the grassland degradation in the latter half of the twentieth century. Furthermore, the variation dynamics of climatic factors are characterized by seasonal and regional heterogeneity; thus, the seasonal variation in grassland types should be analyzed in the next step.

Acknowledgments We thank the China Meteorological Data Sharing Service System and the Western Data Center for providing meteorological data and the AVHRR GIMMS3g NDVI dataset, respectively. This research was funded by the National Natural Science Foundation of China (no. 41501057), West Light Foundation of The Chinese Academy of Sciences, and the Open Fund of the Key Laboratory of Mountain Surface Processes and Ecoregulation.

\section{References}

Caccianiga, M., Andreis, C., Diolaiuti, G., D’Agata, C., Mihalcea, C., \& Smiraglia, C. (2011). Alpine debris-covered glaciers as a habitat for plant life. Holocene, 21, 1011-1020.

Chu, D., Lu, L., \& Zhang, T. (2007). Sensitivity of normalized difference vegetation index (NDVI) to seasonal and interannual climate conditions in the Lhasa area, Tibetan plateau, China. Arctic Antarctic and Alpine Research, 39, 635-641.

Cui, X. F., \& Graf, H. F. (2009). Recent land cover changes on the Tibetan Plateau: a review. Climatic Change, 94, 47-61.

Ding, M. J., Zhang, Y. L., Liu, L. S., Zhang, W., Wang, Z. F., \& Bai, W. Q. (2007). The relationship between NDVI and precipitation on the Tibetan Plateau. Journal of Geographical Sciences, 17, 259-268.

Ding, M. J., Zhang, Y. L., Sun, X. M., Liu, L. S., Wang, Z. F., \& Bai, W. Q. (2013). Spatiotemporal variation in alpine grassland phenology in the Qinghai-Tibetan Plateau from 1999 to 2009. Chinese Science Bulletin, 58, 396-405.

Gao, Q. Z., Wan, Y. F., Li, Y., Qin, X. B., Jiangcun, W., \& Xu, H. M. (2010). Spatial and temporal pattern of alpine grassland condition and its response to human activities in Northern Tibet, China. Rangeland Journal, 32, 165-173.

Gurgel, H. C., \& Ferreira, N. J. (2003). Annual and interannual variability of NDVI in Brazil and its connections with climate. International Journal of Remote Sensing, 24, 35953609 .

Immerzeel, W. W., Quiroz, R. A., \& de Jong, S. M. (2005). Understanding precipitation patterns and land use interaction in Tibet using harmonic analysis of SPOT VGT-S10 NDVI time series. International Journal of Remote Sensing, 26, 2281-2296.

Liu, M., Liu, G. H., Gong, L., Wang, D. B., \& Sun, J. (2014). Relationships of biomass with environmental factors in the grassland area of Hulunbuir, China. Plos One, 9. 
Namgail, T., Rawat, G. S., Mishra, C., van Wieren, S. E., \& Prins, H. H. T. (2012). Biomass and diversity of dry alpine plant communities along altitudinal gradients in the Himalayas. Journal of Plant Research, 125, 93-101.

Nowak, A. S., \& Nobis, M. (2012). Distribution patterns, floristic structure and habitat requirements of the alpine river plant community Stuckenietum amblyphyllae ass. nova (Potametea) in the Pamir Alai Mountains (Tajikistan). Acta Societatis Botanicorum Poloniae, 81, 101-108.

Piao, S. L., Mohammat, A., Fang, J. Y., Cai, Q., \& Feng, J. M. (2006). NDVI-based increase in growth of temperate grasslands and its responses to climate changes in China. Global Environmental Change-Human and Policy Dimensions, 16, 340-348.

Rana, M. S., Samant, S. S., \& Rawat, Y. S. (2011). Plant communities and factors responsible for vegetation pattern in an alpine area of the northwestern Himalaya. Journal of Mountain Science, 8, 817-826.

Schaphoff, S., Heyder, U., Ostberg, S., Gerten, D., Heinke, J., \& Lucht, W. (2013). Contribution of permafrost soils to the global carbon budget. Environmental Research Letters, 8.

Shen, C., Shen, C. M., Liu, K. B., Carrie, M., Overpeck, J. T., Peng, J. L., \& Tang, L. Y. (2008). Ecotone shift and major droughts during the mid-late holocene in the central Tibetan Platenu. Remote Sensing, 89, 1079-1088.

Shen, Z. X., Fu, G., Yu, C. Q., Sun, W., \& Zhang, X. Z. (2014). Relationship between the growing season maximum enhanced vegetation index and climatic factors on the Tibetan plateau. Remote Sensing, 6, 6765-6789.

Sun, J., Cheng, G. W., \& Li, W. P. (2013a). Meta-analysis of relationships between environmental factors and aboveground biomass in the alpine grassland on the Tibetan Plateau. Biogeosciences, 10, 1707-1715.

Sun, J., Cheng, G. W., Li, W. P., Sha, Y. K., \& Yang, Y. C. (2013b). On the variation of NDVI with the principal climatic elements in the Tibetan Plateau. Remote Sensing, 5, 1894-1911.
Sun, J., Wang, X. D., Cheng, G. W., Wu, J. B., Hong, J. T., \& Niu, S. L. (2014). Effects of grazing regimes on plant traits and soil nutrients in an alpine steppe Northern Tibetan Plateau. Plos One, 9.

Venn, S. E., Green, K., Pickering, C. M., \& Morgan, J. W. (2011). Using plant functional traits to explain community composition across a strong environmental filter in Australian alpine snowpatches. Plant Ecology, 212, 1491-1499.

Wang, G. X., Wang, Y. B., Li, Y. S., \& Cheng, H. Y. (2007). Influences of alpine ecosystem responses to climatic change on soil properties on the Qinghai-Tibet Plateau, China. Catena, 70, 506-514.

Wang, G. X., Bai, W., Li, N., Hu, H., Wang, G. X., Bai, W., Li, N., $\&$ Hu, H. C. (2011). Climate changes and its impact on tundra ecosystem in Qinghai-Tibet Plateau, China. Climatic Change, 106, 463-482.

Wang, H. S., Liu, D. S., Lin, H., Montenegro, A., \& Zhu, X. L. (2015). NDVI and vegetation phenology dynamics under the influence of sunshine duration on the Tibetan plateau. International Journal of Climatology, 35, 687-698.

Xu, X. K., CHEN, H., \& LEVY, J. K. (2008). Spatiotemporal vegetation cover variations in the Qinghai-Tibet Plateau under global climate change. Chinese Science Bulletin, 53, 915-922.

Xu, W. X., Gu, S., Zhao, X. Q., Xiao, J. S., Tang, Y. H., Fang, J. Y., Zhang, J., \& Jiang, S. (2011). High positive correlation between soil temperature and NDVI from 1982 to 2006 in alpine meadow of the Three-River Source Region on the Qinghai-Tibetan Plateau. International Journal of Applied Earth Observation and Geoinformation, 13, 528-535.

Zhang, K., Zhao, Y., Zhou, A. F., \& Sun, H. L. (2010). Late Holocene vegetation dynamic and human activities reconstructed from lake records in western Loess Plateau, China. Quaternary International, 227, 38-45.

Zhao, L., Ping, C. L., Yang, D. Q., Cheng, G. D., Ding, Y. J., \& Liu, S. Y. (2004). Changes of climate and seasonally frozen ground over the past 30 years in Qinghai-Xizang (Tibetan) Plateau, China. Global and Planetary Change, 43, 19-31. 